\title{
PESQUISA E EXTENSÃO: A UNIÃO DE ESFORÇOS PARA O ENFRENTAMENTO DOS DESAFIOS DO DESENVOLVIMENTO RURAL
}

\section{RESEARCH AND EXTENSION: THE UNION EFFORTS TO FIGHT THE CHALLENGES OF RURAL DEVELOPMENT}

\author{
Madalena Maria Schlindwein \\ Universidade Federal da Grande Dourados - Dourados - MS - Brasil
}

Adriana Rita Sangalli

Universidade Estadual de Mato Grosso do Sul - Dourados - MS - Brasil

Manfredo Rode

Universidade Federal da Grande Dourados - Dourados - MS - Brasil

Vanda Maria Rubert Stefanello

Universidade Federal da Grande Dourados - Dourados - MS - Brasil

\begin{abstract}
Resumo: A união de esforços de diferentes instituições, com o intuito de encontrar alternativas para solucionar os problemas e fortalecer a agricultura familiar, tem se mostrado uma saída para o desenvolvimento rural. O objetivo deste estudo foi analisar o desenvolvimento do Assentamento Lagoa Grande (em Dourados/MS) a partir da participação da população local e da união de esforços entre pesquisa e extensão. A metodologia baseia-se em pesquisa de campo com utilização de dados primários, obtidos em duas fases: a primeira, com a análise dos dados obtidos junto às famílias assentadas, por meio de aplicação de questionários; e, a segunda, a partir de um projeto de extensão com o intuito de colaborar para a melhoria das condições de vida do assentamento, por meio da realização de oficinas de aprendizagem rural. A partir das dificuldades apontadas na pesquisa, buscou-se, em conjunto com os atores locais, alternativas e soluções para o desenvolvimento rural. Os resultados evidenciam a importância da integração entre as ações de pesquisa e extensão, bem como do trabalho conjunto das diversas entidades para solucionar as deficiências. A oportunidade de diálogo entre os assentados e os representantes de diferentes órgãos possibilitou novos conhecimentos que podem se traduzir em oportunidades, além da
\end{abstract}


conscientização dos agricultores sobre suas atitudes no processo de transformação do assentamento.

Palavras-chave: Agricultura familiar. Desenvolvimento rural. Assentamento rural.

Abstract: The collaboration of different institutions to find alternatives to solve problems and strengthen family farming has proven to be a solution for rural development. The goal of this study was to analyze the cooperative research and extension within the economic development of the Lagoa Grande Rural Settlement (in Dourados/MS) with the participation of its local population. The methodology is based on field research with use of primary data in two phases: the first, with the analysis of data obtained from the families settled through use of questionnaires and the second, from an extension project that contributed to the improvement of living conditions in the settlement through various workshops about rural learning. Due to the difficulties the research identified, we sought alternatives and solutions for rural development together with local stakeholders. The results show the importance of organizations working collaboratively to address problems. The exchange of knowledge between the local residents with the entities of research and extension can lead to new opportunities, as well as guiding farmers' attitudes in the settlement transformation process.

Keywords: Family farming. Rural settlement. Rural development.

\section{INTRODUÇÃO}

A utilização de terras para a produção de alimentos a fim de sanar a fome da população mundial tem sido alvo de pesquisas e de discussões em várias áreas acadêmicas. A FAO' (2012) considera a agricultura familiar como um poderoso segmento da sociedade que pode garantir a segurança alimentar da população mundial na atualidade e, principalmente, para as futuras gerações. Para essa organização mantida pela ONU, o fortalecimento da agricultura familiar é a chave para reduzir a fome e a pobreza, desde que o pequeno produtor tenha acesso à terra, à água, aos mercados, às tecnologias e ao crédito necessários.

De acordo com a Companhia Nacional de Abastecimento - CONAB (2012), a agricultura familiar é responsável por mais de $80,0 \%$ da ocupação no setor rural do Brasil, gerando sete de cada dez empregos no campo, e em torno de $40,0 \%$ da produção agrícola. A maior parte dos alimentos que abastecem a mesa dos brasileiros, na atualidade, é

\footnotetext{
1 Food and Agriculture Organization of the United Nations for a World without Hunger.
} 
oriunda dos pequenos lotes. Essa modalidade de agricultura favorece a utilização de práticas produtivas ecologicamente mais equilibradas, como a diversificação de cultivos, o menor uso de insumos industriais e a preservação do patrimônio genético.

Ao Estado compete analisar e implementar políticas agrícolas e de segurança alimentar que influenciem a ocupação da terra considerando a demografia, os movimentos populacionais e as áreas improdutivas. Deve atuar também no sentido de melhorar as condições de manejo, de produção e de comercialização, mediante a viabilização de redes financeiras rurais, mediante o acesso aos insumos, aos serviços agrícolas e aos mercados e mediante o fomento pesquisas agrícolas (BARBIERI, 2011). Nesse sentido, MacMillan e Benton (2014) observam que os governos devem apoiar as parcerias entre agricultores $\mathrm{e}$ pesquisadores a fim de descentralizar, diversificar e enriquecer a pesquisa e o desenvolvimento agrícola. Destaque-se que os agricultores são os atores essenciais em qualquer sistema de inovação agrícola.

Na observação de Guilhoto (2005), os agricultores familiares são dependentes de apoio governamental. Com ações como políticas de crédito e pesquisas agropecuárias direcionadas aos sistemas de menor escala, assistência técnica, acesso à terra, apoio ao cooperativismo e à educação, essas famílias podem sair da pobreza e alcançar a classe média.

Para Souza et al. (2011), os obstáculos que limitam o desenvolvimento da agricultura familiar, como a escassez de terra, a falta de assistência técnica e a insuficiência de recursos financeiros, também dificultam o alcance do padrão tecnológico necessário para tornar esse segmento competitivo. Os autores destacam que esses fatores são ainda mais evidentes nos assentamentos rurais de reforma agrária.

Verifica-se que existem importantes fatores socioeconômicos e demográficos associados às problemáticas dos assentamentos rurais, tais como: a produtividade do lote, a renda, o quadro familiar, a escolaridade, a capacitação técnica, o associativismo, entre outros. Entender como esses fatores interferem no desenvolvimento desses locais foi a questão motivadora para a realização desta pesquisa.

O grande desafio deste estudo foi identificar a configuração atual do Assentamento Lagoa Grande (em Dourados/MS), retratando os 
anseios e as estratégias de resistência dos assentados, além de suas alternativas de sobrevivência. Nesse ínterim, tem-se como objetivo geral analisar o desenvolvimento desse assentamento a partir da participação da população local e da união de esforços entre pesquisa e extensão rural.

Especificamente, busca-se analisar a relevância da união de esforços de diferentes instituições para o fortalecimento da agricultura familiar e o desenvolvimento das propriedades no assentamento em questão, localizado no Município de Dourados, no Estado de Mato Grosso do Sul. A relevância dessa união de forças visa encontrar alternativas para solucionar os problemas emergenciais do assentamento, problemas que geram desconforto, desânimo, baixa estima e falta de motivação para a continuidade de suas atividades.

Ferraz Junior (2010) ressalta a importância da pesquisa e da extensão nas universidades, com atividades que visem ao desenvolvimento social e econômico do país para a melhoria da qualidade de vida da população, mesmo com as dificuldades que diversas universidades passam, principalmente as federais. $O$ autor pontua que a efetiva atuação dessas instituições integra comunidades ou fornece respostas às mazelas pontuais do Brasil.

Nessa ótica, Pivetta et al. (2010, p. 386) observam que a pesquisa constitui "[...] uma ferramenta indispensável para a geração de novas hipóteses, enraizadas e fundamentadas na vida e nas reais necessidades da população". Em relação à extensão universitária, os autores destacam que seu papel visa estimular e ampliar a rede de interações na comunidade, de forma que os novos conhecimentos produzidos pela pesquisa e a difusão pelo ensino não se limitem às salas de aula e laboratórios, mas que sejam conectados com a realidade social.

Então, o que motivou a realização deste estudo foi a constatação de que, muitas vezes, diversas instituições trabalham no sentido de amenizar problemas e encontrar soluções para o desenvolvimento sustentável na agricultura familiar. No entanto, esses trabalhos acontecem na forma de ações isoladas e, por isso, não alcançam os resultados esperados. Como os objetivos em geral convergem, ficam alguns questionamentos: - Por que não unir esforços para implementar políticas que efetivamente tragam resultados positivos no que se refere à inserção tanto produtiva, quanto social, econômica e política? E, 
especificamente para este trabalho: - Será que essa união de esforços resultará em melhorias no que se refere ao desenvolvimento do Assentamento Lagoa Grande?

Este artigo está organizado em cinco seções incluindo esta breve introdução. Nas seções dois e três, apresenta-se uma revisão bibliográfica. Na quarta seção, destaca-se a metodologia aplicada para a realização do estudo. Na seção cinco, constam os resultados e as discussões acerca da temática em análise. Por fim, apresentam-se as considerações finais e as referências que embasaram a realização deste trabalho.

\section{AGRICULTURA FAMILIAR E A GERAÇÃO DE RENDA NOS ASSENTAMENTOS RURAIS}

A agricultura familiar se articula sob diferentes formas e intensidades entre seus elementos: família, terra e trabalho, adaptandose a diferentes contextos sociais, econômicos e políticos. A junção da propriedade, da gestão, do trabalho e das relações de parentesco no desenvolvimento da produção familiar também se configuram na legislação brasileira. A Lei Federal $n^{0} 11.326$, de 24 de junho de 2006, considera agricultor ou empreendedor familiar rural aquele que desenvolve atividades no meio rural, cuja área não exceda a quatro módulos fiscais, a mão de obra utilizada seja oriunda da própria família e a renda familiar seja originada dessas atividades (BRASIL, 2012).

Os principais fatores que legitimaram a agricultura familiar no Brasil, conforme Manzanal e Schneider (2011), foram: (i) a recuperação da força política do movimento sindical e dos trabalhadores rurais durante a década de 1990, (ii) a criação, em 2006, do Programa Nacional de Fortalecimento da Agricultura Familiar - PRONAF e (iii) a promulgação da Lei da Agricultura Familiar também em 2006.

Na observação de Guilhoto et al. (2006), o mundo contemporâneo colocou o sistema de produção familiar em um contexto socioeconômico próprio e delicado, uma vez que sua importância está relacionada com o futuro das pessoas que dependem do campo, com a problemática do êxodo rural e com a desigualdade social no campo e nas cidades. As diferentes realidades que caracterizam a agricultura familiar brasileira evidenciam a necessidade de políticas públicas diferenciadas, conforme a necessidade de cada região (CARMO; 
COMITRE, 201 1). Nesse contexto, figuram os assentamentos de reforma agrária, projetados a partir da agricultura familiar resultantes de um processo social e econômico com possibilidades de desenvolvimento rural, porém com alto grau de dependência de políticas públicas para sobreviverem e progredirem.

Sempre que, em território nacional, ocorre um projeto de assentamento, esse momento e local demarca o fim de um ciclo e o início de outro. Trata-se de um processo de transformação pelo qual famílias de trabalhadores rurais têm a oportunidade de desenvolver seus projetos de vida, mudando seus destinos e resolvendo o problema da própria sobrevivência (ANDRADE, 1998).

Os objetivos dos projetos de reforma agrária devem observar os fatores que afetam o desenvolvimento das famílias assentadas, como: a fertilidade dos solos, relevo, localização, água, dimensão, armazéns, máquinas e equipamentos, instalações, agroindústrias, sistema de produção adotado, crédito, assistência técnica e o acesso aos serviços básicos (educação, saúde e moradia). Para Bittencourt (1998), a interação entre esses fatores é determinante no desenvolvimento socioeconômico dos assentamentos.

Verifica-se, portanto, a necessidade de um planejamento adequado na criação dos projetos de assentamentos que venham a ser estruturados. Para tanto, tornam-se necessários levantamentos em relação à fertilidade do solo, acesso ao mercado consumidor e disponibilidade de serviços de saúde e educação próximos ou mesmo nesses próprios locais, a fim de proporcionar qualidade de vida mínima aos assentados.

Bittencourt et al. (1998) destacam fatores que potencializaram o desenvolvimento de alguns assentados, como: área com melhor fertilidade, relevo adequado, água acessível, etc.; possuir capital inicial acima da média dos demais assentados; capacidade administrativa, de planejamento e de melhor utilização do crédito agrícola; maior dedicação e trabalho de algumas famílias; escolha de sistemas de produção com mais lucratividade; experiência anterior e capacitação. Como fatores que restringiram o desenvolvimento socioeconômico de alguns assentados, os autores destacam: solos fracos e falta de acesso à água para irrigação ou para o consumo dos animais; ausência de capital inicial ou abaixo da média; crédito agrícola mal utilizado; ausência de 
estradas até o lote ou sem condições de escoamento da produção; falta de experiência e de capacitação e doenças na família, que diminuíram a força de trabalho e aumentaram os gastos.

Nesse sentido, pesquisas envolvendo a área socioeconômica são muito importantes para evidenciar a realidade dos assentamentos rurais e de seus habitantes, promovendo os debates que possam contribuir para a elaboração de políticas públicas de desenvolvimento para os assentamentos rurais, de acordo com a realidade diagnosticada.

A modernização da economia e as exigências dos mercados consumidores obrigam famílias assentadas a tornarem-se mais eficientes nos processos produtivos, reduzindo custos e melhorando a qualidade. Como, no entanto, o porte reduzido das unidades de produção familiares limita a produção em maior escala, tornando ainda mais importante o agrupamento das famílias agricultoras em cooperativas, associações ou outras formas de interação (VILPOUX; OLIVEIRA, 2011).

Entre as tecnologias de baixo custo para a agricultura familiar, Crevelin e Scalco (2007, p. 9) destacam: "[...] utilização do pastejo rotacionado, descarte de animais improdutivos, desmame precoce, práticas de vacinações, controle de parasitas, uso da cana-de-açúcar como volumoso na alimentação animal na época seca, refrigeração do leite e adoção de práticas gerenciais". A adoção de algum sistema alternativo de irrigação costuma tornar-se tecnologia viável e eficiente para a agricultura familiar e tal sistema pode ser confeccionado por meio de potes, xique-xique, mandala, entre outras opções (COELHO et al., 2012). Dessa forma, verifica-se que a adoção dessas alternativas nos assentamentos rurais requer a transferência de conhecimento por profissionais capacitados e o acompanhamento durante a sua implantação.

Nessa perspectiva, constata-se a necessidade de políticas públicas que promovam o desenvolvimento econômico dos assentamentos. A implantação dessas políticas deve prover tanto a capacitação dos produtores quanto deve propor alternativas sustentáveis e viáveis economicamente, conforme as especificidades locais.

As políticas públicas para a orientação dos sistemas produtivos nos assentamentos devem ser direcionadas e sustentadas nos seguintes eixos: fomento, extensão rural qualificada e em quantidade suficiente, 
investimento/logística e segurança alimentar. Dessa forma, podem conduzir a um processo de desenvolvimento econômico democrático, com a participação dos assentados e suas organizações (SILVA, 2012).

Observa-se que as políticas públicas de custeio agrícola são muito importantes para o desenvolvimento dos assentamentos rurais, como o PRONAF, o Programa de Aquisição de Alimentos - PAA, o Programa Nacional de Alimentação Escolar - PNAE, entre outros, que, nos últimos anos, têm contribuído na melhoria da renda familiar de assentados. Ocorre, no entanto, que muitas famílias não têm conhecimento sobre os programas, nem sabem onde buscar informação sobre eles, e acabam perdendo oportunidades importantes para o incremento da produtividade e geração de renda dos seus lotes.

\section{A IMPORTÂNCIA DA PESQUISA E DA EXTENSÃO RURAL NOS ASSENTAMENTOS RURAIS}

Nos assentamentos rurais oriundos dos projetos de reforma agrária, após conquistarem a terra, os assentados defrontam-se com novas incertezas, expectativas e desafios. Muitas famílias nem sequer possuem os meios básicos para os trabalhos mais simples das lidas do campo, pois algumas ferramentas essenciais (como a enxada, o facão e demais instrumentos elementares) são precários e ainda há falta de crédito adequado, falta de sementes e falta de orientação técnica, fatores que tornam impossível a sobrevivência das famílias isoladas (VALADARES et al., 2011).

Muitos assentamentos são instalados em locais sem boas condições de solos e de água, além de inadequado acesso ao mercado consumidor, tornando-se dependentes de políticas públicas para a fixação dos assentados. Para Valadares et al. (2011, p. 136): "É condição imprescindível à formação das políticas públicas voltadas para o desenvolvimento rural o aprimoramento constante das informações relativas aos modos de vida e produção da população do campo".

Dessa forma, os programas de assentamentos precisam ser planejados e estruturados em áreas localizadas em solos férteis, com apoio financeiro na implantação, para a compra de equipamentos e, principalmente, com orientação técnica que forneça o suporte necessário para as atividades produtivas, de agregação de valor e comercialização. 
Para Carvalho (2009), o papel da assistência técnica e extensão rural no Brasil, na atualidade, busca o desenvolvimento sustentável da agricultura familiar, desvencilhando-se cada vez mais das práticas e conceitos de produtividade a qualquer custo. De acordo com Caporal (2009), o Estado necessita atuar efetivamente na promoção de serviços públicos e gratuitos, de assistência técnica e extensão rural para a agricultura familiar e às demais populações excluídas dos países em desenvolvimento.

Alves e Souza (2014) destacam que a extensão rural deve ser chamada e treinada a fim de ajudar as comunidades de assentados de reforma agrária para a mudança de condições no entorno dos estabelecimentos, na perspectiva de resolver as necessidades dessas famílias. Nesse contexto, constata-se a necessidade de políticas públicas que promovam o desenvolvimento dos assentamentos, com a capacitação dos produtores, propondo alternativas sustentáveis e viáveis economicamente, conforme as especificidades locais.

Sturza et al. (2012, p. 8) ressaltam que: "A complexidade do rural no Brasil exige uma extensão rural que contemple as peculiaridades técnicas (o espaço tecnológico), ambientais (o espaço natural, principalmente solo e água) e socioculturais (o espaço vivido)". Os autores destacam ainda que se trata de um desafio para o produtor a mudança de atitudes e adoção de novas tecnologias.

A extensão proporciona a interação de conhecimentos entre os assentados e as instituições, auxiliando na aplicação de técnicas, na gestão e na comercialização da produção. Sturza e Rodrigues (2009) constataram que as comunidades demonstram receptividade e interesse no conhecimento sistematizado, além da vontade de partilhar os saberes tradicionais.

As boas práticas de extensão buscam atender às demandas da agricultura familiar. Esse novo enfoque da extensão fundamenta-se na comunicação entre técnicos e agricultores, objetivando o compartilhamento de informações e conhecimentos técnicos, a fim de capacitar os diferentes atores, melhorando o acesso ao mercado e mantendo a sustentabilidade dos recursos naturais, além de promover o desenvolvimento do capital humano e social da população atendida (FAO, 2011). 
A realidade agrária necessita de profissionais capazes de enfrentar a complexidade da agricultura familiar em todas as suas vertentes e não somente na área técnica (AZEVEDO, 2011). Para Sturza (2013, p. 57): "A pesquisa e a extensão universitária ainda carregam a carga e a responsabilidade de oferecer o conhecimento básico, teórico, conceitual e metodológico de conteúdos e temas de Extensão Rural”. Desse modo, o papel das universidades e demais instituições de ensino, pesquisa e extensão são de fundamental importância para o desenvolvimento da agricultura familiar, em especial nos assentamentos rurais.

\section{METODOLOGIA}

Este trabalho constitui-se de uma análise descritiva, baseada em uma pesquisa de campo, com a utilização de dados primários e pesquisa exploratória, por meio de revisão documental e bibliográfica. A área geográfica refere-se ao núcleo de povoamento rural denominado Assentamento Lagoa Grande, que é um projeto de assentamento federal (PA) criado pela Portaria do INCRA $n^{\circ} 52$, de 6/11/1997, localizado às margens da Rodovia Dourados - Itahum, a cinco quilômetros do distrito de Itahum, no Município de Dourados/MS e conta com uma área total de 4.070 hectares, divididos em 151 lotes.

Os dados primários utilizados no estudo foram obtidos em duas fases. A primeira fase, no período de março de 2011 a março de 2013, consistiu em análise dos dados do diagnóstico socioeconômico e ambiental do projeto de pesquisa vigente à época e que resultou na dissertação de mestrado intitulada: Assentamento Lagoa Grande, em Dourados, MS: aspectos socioeconômicos, limitações e potencialidades para o seu desenvolvimento (SANGALLI, 2013). Nessa pesquisa foram aplicados oitenta e nove (89) questionários às famílias residentes.

A segunda fase resulta do projeto de extensão intitulado Ensaios sobre o desenvolvimento socioeconômico: oficinas no assentamento rural Lagoa Grande, realizado no assentamento nos anos de 2013 e 2014. O projeto consistiu em, além do retorno da pesquisa, levar informações sobre alternativas que pudessem viabilizar uma produção sustentável, canais viáveis de comercialização e organização associativa dos assentados para otimizar os sistemas produtivos. 
O projeto de extensão foi pensado no sentido de dar um retorno às famílias assentadas em relação à pesquisa de campo realizada. Em razão de sua complexidade, foi composto por um grupo interdisciplinar de profissionais e alunos de diferentes instituições: Universidade Federal da Grande Dourados - UFGD (professores, alunos e egressos do Programa de Pós-Graduação em Agronegócios das áreas de administração, agronomia, ciências contábeis e economia), Agência de Desenvolvimento Rural de Mato Grosso do Sul - AGRAER (técnica agropecuária da área de agronomia) e Empresa Brasileira de Pesquisa Agropecuária - EMBRAPA Dourados (pesquisador, biólogo da área de agroecologia). Esse Grupo, com o apoio técnico do Instituto Nacional de Colonização e Reforma Agrária - INCRA e da Secretaria da Agricultura Familiar e Economia Solidária de Dourados - SEMAFES, iniciou os trabalhos no assentamento, bem como uma agenda de reuniões entre os diferentes atores, no sentido de implementar melhorias e sanar deficiências. Em 2013, foram realizadas três oficinas e, em 2014, ocorreu uma reunião denominada "agenda de serviços", no qual foram debatidos diversos assuntos. Após a realização de cada oficina, foi feito um relatório com as principais conclusões e resultados obtidos.

\section{RESULTADOS E DISCUSSÃO}

A discussão dos resultados segue apresentando, primeiramente uma caracterização demográfica das famílias residentes no Assentamento Lagoa Grande. Após isso, são apresentados os fatores relacionados à geração de renda, à importância da união e da assistência técnica para a solução dos problemas. Ainda serão destacados os fatores limitantes e propulsores para o desenvolvimento das propriedades. E, por fim, apresentar-se-ão os resultados obtidos por meio do projeto de extensão.

\subsection{Caracterização demográfica do assentamento}

Para analisar o Assentamento Lagoa Grande, foram entrevistados - como já acima informado - 89 chefes de família ou responsáveis pelos domicílios, residentes nos lotes, dos quais $49(55,1 \%)$ são do sexo masculino e $40(44,9 \%)$ do sexo feminino. A idade dos entrevistados variou de 14 a 85 anos. Na Tabela 1, observa-se que a maior parte dos 
entrevistados pertence à faixa etária entre 41 a 50 anos (30,3\%). Até 40 anos, destacam-se $25,8 \%$ e, com mais que 50 anos, $54 \%$.

A média de idade dos demais membros familiares, que totalizam um grupo de 213 pessoas, é de 20,3 anos, conforme faixas da Tabela 1, sendo que o mais novo tem um mês e o mais velho 84 anos. 
Tabela 1. Idade da população residente no Assentamento Lagoa Grande

\begin{tabular}{|c|c|c|c|c|c|c|}
\hline \multirow[t]{2}{*}{ Faixa etária } & \multicolumn{2}{|c|}{$\begin{array}{c}\text { Chefes ou } \\
\text { responsáveis pelo } \\
\text { domicílio }\end{array}$} & \multicolumn{2}{|c|}{ Membros familiares } & \multicolumn{2}{|c|}{ População total } \\
\hline & $\begin{array}{c}\mathbf{N}^{\mathbf{O}} \\
\text { pessoas }\end{array}$ & $\begin{array}{c}\text { Percentual } \\
(\%) \\
\end{array}$ & $\begin{array}{c}\mathbf{N}^{\circ} \\
\text { pessoas }\end{array}$ & $\begin{array}{c}\text { Percentual } \\
(\%) \\
\end{array}$ & $\begin{array}{c}N^{0} \\
\text { pessoas }\end{array}$ & $\begin{array}{c}\text { Percentual } \\
(\%) \\
\end{array}$ \\
\hline 0 a 10 anos & 0 & - & 30 & 14,1 & 30 & 9,9 \\
\hline $\begin{array}{ll}11 \text { a } 20 \\
\text { anos }\end{array}$ & 1 & 1,1 & 55 & 25,8 & 56 & 18,5 \\
\hline $\begin{array}{ll}21 & \text { a } 30 \\
\text { anos } & \end{array}$ & 3 & 3,4 & 29 & 13,6 & 32 & 10,6 \\
\hline $\begin{array}{ll}31 \text { a } & 40 \\
\text { anos } & \end{array}$ & 10 & 11,2 & 25 & 11,7 & 35 & 11,6 \\
\hline $\begin{array}{ll}41 \text { a } 50 \\
\text { anos }\end{array}$ & 27 & 30,3 & 29 & 13,6 & 56 & 18,5 \\
\hline $\begin{array}{ll}51 \text { a } & 60 \\
\text { anos } & \end{array}$ & 24 & 27,0 & 20 & 9,5 & 44 & 14,6 \\
\hline $\begin{array}{l}\text { Mais de } 60 \\
\text { anos }\end{array}$ & 24 & 27,0 & 25 & 11,7 & 49 & 16,3 \\
\hline Totais & 89 & 100,0 & 213 & 100,0 & 302 & 100,0 \\
\hline
\end{tabular}

Fonte: Elaborada pelos autores a partir de dados da pesquisa.

Verifica-se que o assentamento é composto de uma população jovem, onde se destaca a faixa etária de 11 a 20 anos, com 18,5\% da população, e a faixa de 0 a 10 anos, com 9,9\%, que, juntos, somam $28,4 \%$. Destaque-se que $39 \%$ da população possui até 30 anos de idade. Essa característica é muito importante para o futuro do assentamento e aponta a necessidade de políticas públicas que envolvam a participação desses jovens, principalmente para conscientizá-los quanto ao seu papel no desenvolvimento das propriedades (Tabela 1).

Observa-se ainda, de acordo com os dados da Tabela 1, que $18,5 \%$ da população tem idade entre 41 e 50 anos e que 30,9\% tem mais de 50 anos. Um dado interessante é também o número de idosos no assentamento, sendo que $16,3 \%$ dos moradores possuem mais de 60 anos de idade. Nesse sentido, verifica-se a necessidade de políticas públicas diferenciadas e direcionadas para esse público, que incentivem a permanência dessa população, principalmente os mais jovens, no assentamento, conforme já destacavam Guilhoto et al. (2006).

No que se refere à escolaridade da população residente no assentamento, os dados demonstram que o nível é baixo, sendo que a 
maioria dos chefes de família ou responsáveis pelo domicílio $(43,9 \%)$ possuem apenas educação infantil incompleta ( $1^{\circ}$ ao $5^{\circ}$ ano), seguidos de $14,0 \%$ com ensino fundamental incompleto ( $6^{\circ}$ ao $9^{\circ}$ ano), conforme dados da Tabela 2. Essas faixas também se destacam em relação aos demais membros familiares, com $30,1 \%$ com educação infantil incompleta, seguido do ensino fundamental incompleto, com $24,9 \%$.

Conforme apresentado na Tabela 2, observou-se, durante as entrevistas, que as famílias incentivam seus filhos a estudarem. Entre os membros menores de 18 anos, em idade escolar, apenas um estava fora da escola. O número de universitários entre a população é pequeno $(5,8 \%)$, desmotivados pelas dificuldades de transporte, tendo em vista que o ônibus municipal, que conduz os estudantes do assentamento para Itahum, não transporta universitários. Esses jovens, que na maioria estudam no período noturno, se deslocam por conta própria até Itahum, onde um ônibus fretado os leva para as universidades, em Dourados. Esse fator pode ser determinante para a saída dos jovens do assentamento no intuito de continuarem estudando e buscarem melhores oportunidades no futuro. Essa realidade vai contra uma necessidade primeira da agricultura familiar, que é a de manter a família no campo para o desenvolvimento das atividades, como também destacaram Bittencourt et al. (1998).

Tabela 2. Níveis de escolaridade da população residente no Assentamento Lagoa Grande, em percentual

\begin{tabular}{|c|c|c|c|c|c|c|}
\hline \multirow[t]{2}{*}{ Níveis de Escolaridade } & \multicolumn{2}{|c|}{$\begin{array}{c}\text { Chefes ou } \\
\text { responsáveis pelo } \\
\text { domicílio }\end{array}$} & \multicolumn{2}{|c|}{ Membros familiares } & \multicolumn{2}{|c|}{ População total } \\
\hline & População & (\%) & População & (\%) & População & (\%) \\
\hline Analfabeto & 5 & 5,6 & 8 & 4,3 & 13 & 4,7 \\
\hline Alfabetizado & 7 & 7,9 & 12 & 6,6 & 19 & 6,9 \\
\hline $\begin{array}{l}\text { Educação infantil } \\
\text { incompleta }\left(1^{\circ} \text { a } 5^{\circ} \text { ano }\right)\end{array}$ & 39 & 43,9 & 56 & 30,1 & 95 & 34,8 \\
\hline $\begin{array}{l}\text { Educação infantil } \\
\left.\text { completa ( } 1^{\circ} \text { a } 5^{\circ} \text { ano }\right)\end{array}$ & 8 & 9,0 & 2 & 1,1 & 10 & 3,6 \\
\hline $\begin{array}{l}\text { Ensino fundamental } \\
\text { incompleto ( } 6^{\circ} \text { ao } 9^{\circ} \text { ano) }\end{array}$ & 13 & 14,6 & 46 & 24,9 & 59 & 21,6 \\
\hline $\begin{array}{l}\text { Ensino fundamental } \\
\text { completo }\left(6^{\circ} \text { ao } 9^{\circ} \text { ano }\right)\end{array}$ & 6 & 6,7 & 8 & 4,3 & 14 & 5,1 \\
\hline Ensino médio incompleto & 3 & 3,4 & 22 & 11,9 & 25 & 9,1 \\
\hline Ensino médio completo & 4 & 4,5 & 13 & 7,0 & 17 & 6,2 \\
\hline
\end{tabular}




\begin{tabular}{l|cccccc}
$\begin{array}{l}\text { Educação superior } \\
\text { incompleta }\end{array}$ & 2 & 2,2 & 14 & 7,6 & 16 & 5,8 \\
$\begin{array}{l}\text { Educação superior } \\
\text { completa }\end{array}$ & 2 & 2,2 & 4 & 2,2 & 6 & 2,2 \\
\hline Totais & 89 & 100 & 185 & 100 & 274 & 100 \\
\hline
\end{tabular}

Fonte: Elaborada pelos autores a partir de dados da pesquisa.

Em termos de tempo de experiência de trabalho no meio rural antes do assentamento, a maioria dos chefes de família $(71,9 \%)$ trabalhou somente no meio rural durante sua vida e apenas $8,9 \%$ tinham experiência inferior a 15 anos no campo, sendo que o menor tempo de experiência observado foi de 3 anos. Dentre as ocupações anteriores ao assentamento, destacam-se as funções de empregado de fazenda, com $46,1 \%$, e agricultor proprietário, com 15,6\%.

\subsection{Geração de renda, união e assistência técnica}

No que se refere à forma de obtenção dos lotes, dos entrevistados, 67,4\% disseram que são originários do INCRA e 32,6\% foram adquiridos de terceiros, sendo que $50,6 \%$ são os primeiros proprietários, desde 1997. Verificou-se que nenhum assentado entrevistado possui documento de titularidade do lote. Eles possuem apenas um documento denominado Carta de Anuência, a qual designa o lote em nome do assentado.

A área de cada lote do assentamento varia de 17 a 90 hectares, com uma média de 25,9 ha, sendo que a maioria $(21,3 \%)$ possui 20 ha. Apenas cinco lotes $(5,6 \%)$ possuem mais que 30 ha. Essa divergência nos tamanhos deve-se às áreas de preservação permanente que são muito mais extensas em alguns lotes, os quais são, então, compensados em maior área total.

Em relação às atividades produtivas, apesar de serem diversificadas no assentamento como um todo, na maioria dos lotes a renda gira em torno de um ou dois produtos, além de algumas atividades de produção apenas para o consumo familiar, como a criação de galinhas e porcos, produção de ovos, hortaliças, frutas, mandioca e cana-de-açúcar, esta última especificamente para a alimentação do gado. Essa produção para subsistência é mais acentuada nos lotes de famílias de casais aposentados. Ressalta-se que, em muitos lotes onde não foi possível aplicar o questionário devido à ausência de pessoas no 
local nos dias das visitas, observou-se que também não havia sinais de atividades agrícolas. Conforme informações de vizinhos, alguns desses lotes servem de residência para descanso da família nos fins de semana e, em outros, verificou-se a presença de gado de corte, sendo, segundo os vizinhos, pessoas de lotes próximos contratadas para alimentar o gado diariamente.

Dentre as atividades produtivas mais desenvolvidas no assentamento (gado leiteiro, gado de corte, milho, soja, mandioca e eucalipto), a produção de leite é a atividade econômica de maior representatividade e também a que mais sofreu críticas durante as entrevistas. As principais reclamações envolvem o preço baixo pago pelo leite e a baixa produtividade das vacas, em virtude da má qualidade da pastagem, do solo e da genética do rebanho. Essas características também estão presentes na criação de gado de corte: a segunda atividade produtiva mais praticada no assentamento.

O cultivo de eucalipto é a atividade menos representativa no assentamento, sendo que, em alguns lotes, apresenta-se em sistema agroflorestal. Essa atividade tende a crescer mais, considerando que os agricultores que nela investiram estão satisfeitos com o retorno financeiro e com a menor necessidade de trabalho para a sua produção.

A Figura 1 apresenta, em termos percentuais, as principais atividades produtivas para a geração de renda no assentamento. Destaca-se a criação de gado leiteiro (66\%), gado de corte $(14,5 \%)$, lavoura de soja/milho $(5,6 \%)$, lavoura de mandioca $(4,5 \%)$ e o cultivo de eucalipto (4,5\%), uma atividade recente em expansão. As demais rendas $(4,9 \%)$ são compostas da venda de novilhos $(1,2 \%)$, frangos $(1,1 \%)$, porcos $(1,1 \%)$ e ovos, queijo, doces, mel, pães e artesanato $(1,5 \%)$, que são vendidos conforme a necessidade. O predomínio da pecuária leiteira no Assentamento Lagoa Grande também foi identificado no estudo de Castro et al. (2010).

Destaque-se a baixa diversificação produtiva observada nas propriedades, diversificação essa de extrema importância para o desenvolvimento e a ampliação da renda das famílias. Esse fato também foi detectado no estudo de Santos (2009), que destaca a eficiência produtiva como forma de elevar a renda média e reduzir o êxodo rural. Nessa ótica, Bittencourt (1998) e Silva (2011) observam o dilema enfrentado nos assentamentos ao se proporem converter seus sistemas 
de produção e torná-los viáveis para o autoconsumo e a geração de renda. 
Figura 1. Representatividade das principais atividades produtivas desenvolvidas pelas famílias no Assentamento Lagoa Grande

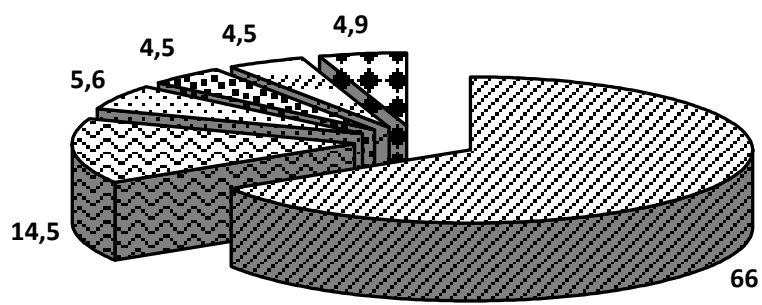

G Gado leiteiro $\Delta$ Gado de corte QSoja/milho Mandioca Eucalipto Z Demais rendas

Fonte: Elaborada pelos autores a partir de dados da pesquisa.

Vale salientar que alguns assentados não possuem nenhuma atividade, na propriedade, que gere renda. É o caso de algumas famílias de aposentados e de pessoas que apenas moram no assentamento, sendo que trabalham na vila (Itahum), nas fazendas do entorno ou em Dourados.

Considere-se, ainda, a dificuldade para os entrevistados responderem às questões referentes à quantidade produzida, ao custo da produção e à renda obtida anualmente. E, principalmente, o custo dessa produção, especificamente pelos produtores de leite, devido à oscilação do produto e à consequente variação do preço no mercado durante o ano. Nesse ponto, observa-se a importância e a necessidade de gestão da propriedade pautada nos enfoques de Crevelin e Scalco (2007).

No que se refere à quantidade produzida, entre as atividades produtivas desenvolvidas no assentamento, conforme a Tabela 3 , destacou-se a produção de leite, com média diária variando entre 10 a 150 litros/dia. Em média, os produtores possuem 21 cabeças de gado leiteiro, que, em sua maioria $(19,4 \%)$, produzem 50 litros/dia. A produtividade por vaca varia de 0,3 a 5 litros/dia, sendo mais frequente de 2 a 3 litros por vaca/dia, e, em 13,3\%, a média produtiva foi de 2 litros vaca/dia, o que representa uma baixíssima produtividade por vaca.

Destaca-se ainda que apenas cinco produtores de leite $(8,5 \%)$ souberam responder sobre o custo de produção, que ficou em média R\$ 
0,15 por litro ( $25,0 \%$ da receita), variando de $10,0 \%$ a $50,0 \%$. A produção anual variou de 3.650 a 54.750 litros, em média 15.389 litros, sendo que $55,0 \%$ produziram até 7.300 litros/ano. O preço pago variou de $R \$$ 0,45 a $R \$ 0,70$, em média $R \$ 0,60$ o litro, ficando uma renda anual entre $R \$ 2.040,00$ e $R \$ 36.000,00$, sendo que $50,0 \%$ obtiveram uma renda de até $R \$ 4.200,00$ por ano. Esse certamente é um rendimento baixíssimo, principalmente por ser uma importante atividade produtiva praticada em $66 \%$ dos lotes.

Entre as atividades produtivas destacadas na Tabela 3, a lavoura de mandioca foi a que proporcionou melhor renda, conforme os dados da pesquisa, sendo fonte principal de geração de renda de apenas três produtores entrevistados, que a cultivam em áreas entre 15 e 19 ha e obtiveram a média produtiva de $80.712 \mathrm{~kg}$ ao ano. O cultivo de eucalipto para venda de madeira é uma fonte de renda em processo inicial e que vem crescendo no assentamento. A maioria das plantações ocupa em média 6,3 ha, variando de 1 a 20 ha e ainda não chegaram ao final do ciclo produtivo (5 anos). Fica o questionamento de por que essas atividades não serem desenvolvidas de forma mais intensa nas propriedades.

Tabela 3. Principais atividades agropecuárias produtivas geradoras de renda nos lotes do Assentamento Lagoa Grande (valores médios anuais)

\begin{tabular}{|c|c|c|c|c|c|c|}
\hline $\begin{array}{l}\text { Culturas } \\
\text { /animais }\end{array}$ & $\begin{array}{c}\text { Área ou } \\
\text { quantidade }\end{array}$ & $\begin{array}{c}\text { Produção } \\
\text { Anual }\end{array}$ & $\begin{array}{c}\text { Renda } \\
\text { Bruta } \\
\text { Anual }\end{array}$ & $\begin{array}{c}\text { Custo de } \\
\text { Produção } \\
\text { Anual }\end{array}$ & $\begin{array}{c}\text { Renda } \\
\text { Líquida } \\
\text { Anual }\end{array}$ & $\begin{array}{c}\text { Renda } \\
\text { Líquida } \\
\text { Mensal }\end{array}$ \\
\hline $\begin{array}{l}\text { Gado } \\
\text { leiteiro }\end{array}$ & 21 cabeças & $\begin{array}{r}16.243 \\
\text { litros }\end{array}$ & $9.745,80$ & $\begin{array}{r}2.436,45 \\
(25,0 \%)\end{array}$ & $7.309,35$ & 609,11 \\
\hline $\begin{array}{l}\text { Gado de } \\
\text { corte }\end{array}$ & 46 cabeças & 12 cabeças & $\begin{array}{r}12.000,0 \\
0\end{array}$ & $\begin{array}{r}2.040,00 \\
(17,0 \%)\end{array}$ & $9.960,00$ & 830,00 \\
\hline Milho & 16,7 ha & 835 sacas & $\begin{array}{r}10.020,0 \\
0\end{array}$ & $\begin{array}{r}2.505,00 \\
(25,0 \%)\end{array}$ & $7.515,00$ & 626,25 \\
\hline Soja & & 410 sacas & $\begin{array}{r}16.400,0 \\
0\end{array}$ & $\begin{array}{r}6.560,00 \\
(40,0 \%)\end{array}$ & $9.840,00$ & 820,00 \\
\hline $\begin{array}{l}\text { Mandioc } \\
\text { a }\end{array}$ & 17,7 ha & $80.712 \mathrm{~kg}$ & $\begin{array}{r}31.477,6 \\
8\end{array}$ & $\begin{array}{r}20.985,12 \\
(66,7 \%)\end{array}$ & $10.492,56$ & 874,38 \\
\hline Eucalipto & 6,3 ha & $1.260 \mathrm{~m}^{3}$ & $\begin{array}{r}50.400,0 \\
0 *\end{array}$ & $\begin{array}{r}18.900,00 \\
(37,5 \%)\end{array}$ & $6.300,00$ & 525,00 \\
\hline
\end{tabular}

Fonte: Elaborada pelos autores a partir de dados da pesquisa.

* Renda obtida após cinco anos (ciclo produtivo). 
Uma atividade que vem ganhando destaque é a produção de doces e de licores de frutos do cerrado. Essa atividade surgiu a partir de projetos da Faculdade de Ciências Biológicas da UFGD, visando à conservação do bioma cerrado no assentamento. Em fevereiro de 2012, cinco famílias apoiadas por professores e alunos da UFGD se juntaram para montar uma associação, a qual entrou em funcionamento no fim deste mesmo ano e denomina-se "Associação Sabores do Cerrado do Assentamento Lagoa Grande em Itahum - MS" - conhecida como Associação Sabores do Cerrado. Esses assentados produzem doces e licores à base de frutos do cerrado, que são coletados em plantas nativas de áreas protegidas em seus lotes. A comercialização é feita por intermédio da economia solidária no campus da UFGD e em eventos e feiras da agricultura familiar, dentro e fora do estado. Merece destaque a cozinha industrial, que se encontra em construção em um dos lotes do assentamento. Essa cozinha será destinada à produção de doces de leite e frutas, licores, bolachas, pães e artesanatos. Esse empreendimento certamente irá contribuir para a melhoria do nível de rendimento das famílias. A maioria dos participantes da associação segue os princípios da produção agroecológica. São alternativas de sobrevivência fundamentadas por Lazzaretti (2003) e que geram rendas extras, necessárias para suprir as necessidades familiares, conforme abordam Guanziroli et al. (2001) e Silva (2002).

A comercialização da produção é um grande problema para os assentados, pois o principal mercado consumidor (Dourados) localizase a $70 \mathrm{~km}$ do assentamento e a vila (Distrito de Itahum), a $5 \mathrm{~km}$. Como muitos assentados não possuem veículo, o escoamento da pequena produção é feito de carroça ou de motocicleta até Itahum, e veículo particular ou de ônibus, para Dourados (linha que funciona somente três dias por semana). As famílias que trabalham com os produtos do cerrado se revezam durante os dias de semana com suas idas para Dourados, a fim de vender seus produtos na feira de economia solidária em funcionamento na UFGD.

A UFGD é um local muito importante para a comercialização de produtos do assentamento (alimentícios e artesanato), onde algumas famílias se revezavam para comercializar a produção com o público da Cidade Universitária, composta pela Universidade Federal e pela Universidade Estadual. 
Assim, portanto, o escoamento da produção é feito de diversas formas, sendo que a maioria utiliza moto $(25,9 \%)$, seguido de carro $(18,5 \%)$, venda direta no lote $(18,5 \%)$, caminhão de frigorífico ou armazém $(14,8 \%)$, carroça $(11,1 \%)$, ônibus $(6,2 \%)$, resfriador instalado no lote $(3,7 \%)$ e bicicleta (1,2\%). A produção é armazenada principalmente nos resfriadores $(63,1 \%)$ no caso do leite, $24,6 \%$ no lote e $12,3 \%$ em armazém ou depósito.

A renda da população residente no Lagoa Grande é composta pela renda do lote e pela renda complementar (Tabela 4). A maioria dos entrevistados $(41,6 \%)$ obtém rendimento do lote inferior a um salário mínimo, que, na época da entrevista, estava em $R \$ 622,00$. Apenas $6,7 \%$ obtêm renda do lote superior a três salários mínimos.

A renda complementar faz parte de $75,3 \%$ das famílias do assentamento, que, em $34,3 \%$ dos casos, gira em torno de um salário mínimo, conforme dados da Tabela 4. Em relação à renda total, verifica-se que $48,3 \%$ dos entrevistados possuem renda familiar de um a dois salários mínimos por mês.

Tabela 4. Fonte de renda mensal das famílias do Assentamento Lagoa Grande (salário mínimo em vigor: $R \$ 622,00$ )

\begin{tabular}{l|c|c|c|c|c|c}
\hline \multirow{2}{*}{$\begin{array}{c}\text { No de salários } \\
\text { mínimos }\end{array}$} & \multicolumn{3}{|c|}{ Renda do lote } & \multicolumn{2}{c}{$\begin{array}{c}\text { Renda } \\
\text { complementar }\end{array}$} & \multicolumn{2}{c}{ Renda Total } \\
\cline { 2 - 7 } & Freq. & Perc. (\%) & Freq. & Perc. (\%) & Freq. & Perc. (\%) \\
\hline Menos de 1 SM & 37 & 41,6 & 17 & 25,4 & 7 & 7,9 \\
1 SM & 14 & 15,7 & 23 & 34,3 & 7 & 7,9 \\
De 1 a 2 SM & 25 & 28,1 & 20 & 29,9 & 43 & 48,3 \\
De 2 a 3 SM & 7 & 7,9 & 5 & 7,5 & 20 & 22,5 \\
Mais de 3 SM & 6 & 6,7 & 2 & 3,0 & 12 & 13,5 \\
\hline Total & 89 & 100,0 & 67 & 100,0 & 89 & 100,0 \\
\hline
\end{tabular}

Fonte: Elaborada pelos autores a partir de dados da pesquisa (Legenda: Freq.= frequência, Perc. $=$ percentual).

No que se refere especificamente à renda complementar, destaca-se a aposentadoria como a principal fonte em $38,8 \%$ das famílias, sendo, em alguns casos, a única fonte de renda, já que muitos aposentados que residem no assentamento só desenvolvem atividades produtivas para a sua subsistência. Dos agricultores que trabalham fora da propriedade, a maioria (39,1\%) possui renda entre um e dois salários mínimos, valor que também se destaca entre os que trabalham 
somente no lote, com 51,5\%. O alto grau de dependência de aposentadorias e pensões também foi detectado por Almeida (2008) em pesquisa realizada em outros seis assentamentos de Mato Grosso do Sul.

A assistência técnica por parte da agência de extensão rural do estado é precária no Lagoa Grande, pois apenas 18,8\% dos entrevistados disseram receber visita de técnicos. Desses, 1,1\% recebe assistência particular e o restante da AGRAER, dos quais 68,7\% declaram ser boa, $12,5 \%$ consideram a assistência regular, $12,5 \%$, ruim e 6,3\%, ótima.

Destaca-se que a assistência técnica poderia melhorar consideravelmente a situação de muitos lotes no assentamento se as orientações fossem especializadas (principalmente por agrônomos e veterinários) e informações sobre alternativas adequadas às características do lote, bem como sobre os programas sociais, dos quais os assentados poderiam participar. Verifica-se que, em geral, os agricultores desconhecem ou são carentes de informações.

Em relação ao associativismo, o Assentamento Lagoa Grande possui duas associações, sendo a Associação de Moradores, da qual participam 66,3\% dos entrevistados, e a Associação Sabores do Cerrado, criada em 2012, da qual participam 5,6\% dos entrevistados, que também participam da associação de moradores.

É importante destacar que uma associação no assentamento deveria ser um elo, a fim de fazer a ponte entre os assentados e as instituições públicas, por meio de parcerias, informando e motivando os assentados a participarem de projetos e programas de geração de renda, bem como contribuir para minimizar ou extinguir muitos dos fatores limitantes ao desenvolvimento das propriedades destacados pelos agricultores. Por outro lado, alguns assentados se declararam pouco participativos e conscientes de que deveriam ser mais unidos e atuantes em prol do bom desempenho da associação.

É importante destacar que os dados desta pesquisa corroboram a abordagem apresentada por Lamas et al. (2000), abordagem que, em pesquisa realizada em 11 assentamentos no Estado de Mato Grosso do Sul, constatou a necessidade de conscientização por parte dos assentados para uma maior organização e atuação em suas associações. Observa-se que o fortalecimento da associação e o resgate da credibilidade pelos assentados nessa entidade podem proporcionar 
perspectivas futuras de melhorias nas propriedades e, assim, conduzir a um processo de desenvolvimento socioeconômico.

\subsection{Entraves ao desenvolvimento do assentamento}

Quando questionados sobre os problemas enfrentados em suas propriedades, foram apontadas muitas dificuldades, que vão discriminadas na Tabela 5. Dos entrevistados, 88,1\% consideram que não existe apoio no assentamento para diminuir essas dificuldades. Os outros 11,9\% consideram que o apoio existe, pela família e, principalmente, por instituições como a AGRAER, a UFGD, a EMBRAPA e a Prefeitura Municipal.

Destaca-se também a falta de incentivos governamentais, tanto no que se refere a financiamentos para a produção quanto para efetuar melhorias de infraestrutura nos lotes do assentamento. Esses resultados inserem-se nas abordagens de Souza et al. (2011), que apontam os obstáculos que limitam o desenvolvimento dos assentamentos e de Valadares et al. (2011), que destacam a necessidade da formação de políticas públicas voltadas para o desenvolvimento rural por meio de acompanhamento e suporte do Estado a fim de proporcionar perspectiva futura e qualidade de vida nos assentamentos. 
Tabela 5. Dificuldades enfrentadas nos lotes do Assentamento Lagoa Grande

\begin{tabular}{|c|c|}
\hline \multicolumn{2}{|l|}{ Dificuldades enfrentadas nos lotes } \\
\hline Respostas & Percentual (\%) \\
\hline Estradas ruins, falta de maquinário e de assistência técnica & 20,2 \\
\hline Pastagem de baixa qualidade & 13,5 \\
\hline $\begin{array}{l}\text { Estradas ruins e falta de transporte para universitários } \\
\text { (noturno) }\end{array}$ & 10,1 \\
\hline Estradas e ponte em péssimas condições & 7,9 \\
\hline Falta de recursos financeiros para investir no lote & 7,9 \\
\hline Necessidade de financiamentos menos burocráticos & 5,6 \\
\hline Falta de incentivo do governo para se manter no lote & 5,6 \\
\hline Falta de transporte, assistência técnica e médica & 5,6 \\
\hline Solo necessitando de adubação e baixa produtividade & 4,5 \\
\hline Necessidade de financiamento para correção do solo & 3,4 \\
\hline Falta de uma cooperativa no assentamento & 3,4 \\
\hline Falta de interação entre os assentados & 2,2 \\
\hline Preço do leite muito baixo & 2,2 \\
\hline Não tem dificuldades & 7,9 \\
\hline
\end{tabular}

Fonte: Elaborada pelos autores a partir de dados da pesquisa.

Salienta-se que a maior dificuldade apontada pelos assentados, com $20,2 \%$ das respostas, engloba as péssimas condições das estradas do assentamento, a falta de maquinário para as atividades agrícolas (principalmente trator e colheitadeira) e a quase inexistência de assistência técnica. A baixa qualidade da pastagem é a segunda maior dificuldade dos assentados, com 13,5\%, fato que prejudica a produtividade e qualidade do leite e a engorda do gado de corte. Observa-se que apenas 7,9\% dos entrevistados consideram que não há dificuldades nas suas atividades do dia a dia no assentamento.

Entre as ações necessárias apontadas pelos entrevistados para ajudar a diminuir essas dificuldades, destaca-se, com 63,0\%, a união e a participação dos moradores na associação do assentamento, e o seu próprio empenho para a resolução dos problemas. Isso mostra a consciência dos moradores do assentamento no que se refere ao seu papel no processo de desenvolvimento das propriedades. Foram citados ainda fatores como a necessidade de uma liderança atuante na associação; a criação de uma cooperativa; a busca de incentivos e auxílio do governo; e a disponibilidade de maquinários, por parte da associação, para empréstimos aos agricultores. 


\subsection{A união de esforços na busca de resultados efetivos no assentamento}

A partir da constatação das dificuldades, problemas e perspectivas das famílias do Assentamento Lagoa Grande, por meio do diagnóstico socioeconômico realizado e apresentado acima, sentiu-se a necessidade de dar uma resposta às famílias e contribuir com o seu desenvolvimento. Para tanto, elaborou-se o projeto de extensão, cujas atividades e ações são descritas a seguir.

O homem do campo já há muito tempo cansou de promessas, de políticas às quais, muitas vezes, ele não tem acesso, principalmente por não se enquadrar nas exigências para a sua implementação. Especificamente no caso do Assentamento Lagoa Grande, percebeu-se essa descrença por parte dos moradores no que se refere às perspectivas de soluções efetivas para sanar suas deficiências. Nesse contexto, após o levantamento das informações junto aos produtores rurais, sentiu-se a necessidade de fazer algo a mais.

Não basta levantar os problemas, é preciso mostrar soluções e, mais que isso, participar efetivamente do processo de implementação de ações que levem às mudanças necessárias. Nessa perspectiva, identificou-se que diversas entidades estavam realizando algum tipo de ação no assentamento, todos com o intuito de colaborar, mas que, de forma isolada, essas ações não teriam o resultado esperado. Assim, foi iniciado um trabalho conjunto entre representantes de entidades, como a UFGD, a AGRAER, a Secretaria da Agricultura Familiar do Município de Dourados, a Unidade do INCRA desse município e, principalmente, os agricultores moradores do assentamento.

$O$ intuito desse trabalho era o de contribuir efetivamente no processo de inclusão produtiva e de desenvolvimento nas propriedades do assentamento. Para isso, foram realizadas três oficinas no ano de 2013 e uma "agenda de serviços" em 2014. A primeira oficina do projeto de extensão foi realizada em 4 de julho de 2013, a segunda em 8 de agosto e a terceira em 3 de dezembro de 2013. A primeira agenda de serviços ocorreu em 5 de maio de 2014 e todos os eventos foram realizados na sede da Associação de Moradores do assentamento. 
Nas oficinas, foram debatidos os seguintes assuntos: (i) a situação do assentamento a partir dos resultados do diagnóstico socioeconômico e ambiental; (ii) Cadastro Único (além de esclarecida a sua importância, uma equipe de profissionais do Centro de Referência e Assistência Social - CRAS participou de uma oficina, tirando dúvidas, realizando e atualizando cadastros); (iii) programas sociais para inserção produtiva (PAA e PNAE); (iv) georreferenciamento e cronograma de trabalho do INCRA para a titularidade dos lotes; (v) correção do solo com calcário e projeto de implantação de hortas tipo mandala apoiados pela SEMAFES e AGRAER; (vi) esclarecimentos sobre o Programa Nacional de Habitação Rural - PNHR; (vii) Declaração Anual de Produção - DAP e Relação de Beneficiários - RB; e (viii) associativismo e cooperativismo.

No evento denominado Agenda de Serviços, ocorreu o lançamento oficial da parceria prefeitura/INCRA, que visava a realização das vistorias nos lotes para posterior titularidade. Também foram debatidos os seguintes assuntos: (i) situação de dívidas de Pronaf junto ao Banco do Brasil (renegociação e condições para liquidação); (ii) implantação de dez hortas orgânicas (tipo mandala) e (iii) implantação de seis tanques de piscicultura pela SEMAFES no assentamento.

Ao final de cada evento, foi passado um questionário avaliativo aos participantes, onde os assentados podiam opinar sobre a relevância dos temas e sugerir assuntos de interesse para as próximas oficinas, além de períodos e locais mais oportunos para a realização desses eventos. Os principais temas sugeridos pelos assentados para as oficinas foram: associativismo e cooperativismo, titularidade dos lotes, Programas PAA e PNAE, Sistema de integração lavoura-pecuáriafloresta, agroecologia e, enfim, agricultura orgânica.

No planejamento de cada evento, o grupo de trabalho - composto de integrantes das diferentes instituições (UFGD, AGRAER, INCRA, SEMAFES e EMBRAPA) - se reunia e, por meio dos questionários, avaliava o evento anterior e, principalmente, as sugestões e reclamações dos assentados, antes de programar os assuntos do próximo evento.

O número de participantes cresceu consideravelmente desde a primeira oficina e a satisfação com o evento também. Muitos participantes sugeriram a realização de oficinas com maior frequência, tanto que, em 2013, estavam programadas duas e ocorreram três. Em 2015 , deveria ter acontecido uma última oficina para avaliar o projeto 
como um todo, porém, em virtude da greve ocorrida na Universidade, esse evento foi prejudicado e deverá ocorrer somente em 2016.

Durante as oficinas, ocorreram debates entre os assentados e os representantes das instituições parceiras em torno das demandas mais emergenciais do assentamento. Foram ainda apresentadas alternativas visando contribuir para o desenvolvimento econômico, social e ambiental das propriedades.

O Assentamento Lagoa Grande apresenta grandes dificuldades que desafiam a permanência dos assentados nos seus lotes. Possibilitar a essa população debates com profissionais de órgãos diretamente ligados à pesquisa e extensão universitária, que apresentem diferentes oportunidades de geração de renda e gestão de suas propriedades, pode contribuir concretamente para minimizar os gargalos e seguir na direção do desenvolvimento de seus lotes.

Destaque-se que, no início desse processo, foi verificado que os diferentes atores, instituições, buscavam alternativas para solucionar os problemas no assentamento, mas cada qual de forma isolada. Verificouse que os objetivos eram comuns e que, se houvesse a união de esforços das diversas instituições (Universidade, AGRAER, INCRA, Secretaria da Agricultura Familiar e Economia Solidária, com o apoio da EMBRAPA, do SEBRAE, entre outros), em conjunto com os atores centrais do processo - os agricultores, se chegar-se-ia de forma mais rápida a resultados positivos. $\mathrm{E}$ foi isso que aconteceu, evidenciando a importância do trabalho conjunto das diversas entidades para solucionar as deficiências, bem como a ação efetiva dos próprios moradores, que se conscientizaram de seu papel no processo de transformação.

\section{CONSIDERAÇÕES FINAIS}

A questão central deste estudo foi mostrar que, para que a inclusão produtiva ocorra de forma efetiva, é necessário que as instituições dialoguem mais. Se os atores trabalharem de forma isolada, certamente os resultados ficarão aquém do esperado e do que poderia ser obtido com a união de esforços.

O diagnóstico socioeconômico oriundo da pesquisa realizada no Assentamento Lagoa Grande, no Município de Dourados, em Mato Grosso do Sul, constatou grandes demandas a serem supridas ou, pelo 
menos, minimizadas e que são comuns à maioria dos assentamentos de reforma agrária brasileiros.

Diante da falta de assistência técnica, que deveria ser proporcionada pelo Estado de maneira a contribuir com os fatores produtivos dos lotes, que, em sua maioria, possuem solos degradados, bem como pela descrença por parte dos assentados na Associação de Moradores, as oficinas de extensão rural promovidas pela universidade surgem como um recurso de apoio na tentativa de colaborar com a resolução dos problemas emergenciais no assentamento. $O$ espaço de diálogo, criado por meio das parcerias, não se restringia somente às oficinas, mas também antes e após a realização delas. O grupo de trabalho se reunia e discutia as temáticas referentes ao andamento dos trabalhos dificuldades e progressos obtidos, além de planejar a continuidade dos trabalhos, com o intuito de contribuir para sanar ou diminuir as deficiências do assentamento.

É importante ressaltar que a união de esforços por meio da pesquisa e da extensão universitária trouxe resultados positivos para o assentamento, já visíveis durante o primeiro ano de sua execução. Esse foi o caso, por exemplo, do início do processo de titularidade dos lotes, - caso da construção de uma ponte de concreto há muitos anos reivindicada pelos assentados e o caso de muitas perspectivas futuras de inclusão produtiva e incremento na produtividade dos lotes, com a disponibilização de maquinários para a construção de hortas e de açudes, isso por meio do incentivo da SEMAFES do município.

Por fim, destaque-se que os trabalhos no assentamento ainda não foram concluídos e que a ação conjunta dessas entidades continua. Nesse sentido, sugere-se a realização de estudos futuros para continuar avaliando os muitos resultados positivos que ainda se esperam.

\section{REFERÊNCIAS}

ALMEIDA, Rosemeire Aparecida de. "Reforma Agrária e produção de autoconsumo em assentamentos rurais no município de Santa Rita do Pardo/MS". In: ALMEIDA, Rosemeire Aparecida. A questão agrária em Mato Grosso do Sul: uma visão multidisciplinar. Campo Grande, MS: Ed. UFMS, 2008. 
ALVES, Eliseu; SOUZA, Geraldo da Silva e. Desafios da Agência de Extensão Rural. In: BUANAIN, Antônio Márcio et al. O mundo rural no Brasil do século 21: a formação de um novo padrão agrário e agrícola. Brasília, DF: Embrapa / Ed. Técnicos, 2014.

ANDRADE, T. Construindo o futuro: política de investimentos em assentamentos rurais, seus custos e resultados. Secretaria da Justiça e da Defesa da Cidadania. Cadernos ITESP - n. 10, São Paulo, 1998.

AZEVEDO, E. O. Desafios e perspectivas da agroecologia. CAPORAL, F. R.; AZEVEDO, E. O. (Orgs.). Princípios e perspectivas da agroecologia. Curitiba, PR: Instituto Federal de Educação, Ciência e Tecnologia do Paraná. Educação a Distância, 2011.

BARBIERI, J. C. Desenvolvimento e meio ambiente: as estratégias de mudanças da agenda 21. 12. ed. Petrópolis, RJ: Vozes, 2011.

BITTENCOURT, A. G. et al. Principais fatores que afetam o desenvolvimento dos assentamentos de reforma agrária no Brasil. In: GUANZIROLI, C. (Coord.). Projeto de Cooperação Técnica INCRA/FAO. Brasília, agosto/1998. Disponível em: $<$ http://www.deser.org.br/pub_read.asp?id=67>. Acesso em: 7 jan. 2013.

BRASIL. Lei $n^{\circ} 11.326$ de 24 de julho de 2006. Estabelece as diretrizes para a formulação da Política Nacional da Agricultura Familiar e Empreendimentos Familiares Rurais. 2012. Disponível em: $<$ http://www.planalto.gov.br/ccivil $\quad$ _03 /_ato20042006/lei/111326.htm>. Acesso em: 6 fev. 2012.

CAPORAL, F. R. (Coord.). Extensão rural e agroecologia: temas sobre um novo desenvolvimento rural, necessário e possível. Brasília, 2009.

CARMO, M. S.; COMITRE, V. A visão sistêmica na avaliação sócioambiental de assentamentos rurais. In: BERGAMASCO, S. M. P. P.; OLIVEIRA, J. T. A.; ESQUERDO, V. F. S. Assentamentos rurais no século 
XXI: temas recorrentes. Campinas, SP: FEAGRI/UNICAMP; São Paulo: INCRA, p. 435-452, 2011.

CARVALHO, D. Desenvolvimento sustentável. Revista Desafios do Desenvolvimento. São Paulo: IPEA, n. 49. p. 56-63, 2009.

CASTRO, K. N. C. et al. Características da pecuária leiteira no Assentamento Fazenda Nova Lagoa Grande, em Dourados, MS. Dourados, MS: Embrapa Agropecuária Oeste, 2010. 44 p. (Embrapa Agropecuária Oeste, Documentos, 106).

COELHO, E. F. et al. Sistemas de irrigação para a agricultura familiar. Cruz das Almas, BA: Embrapa (Embrapa Cruz das Almas, Circular Técnica 106), 2012.

CONAB - Companhia Nacional de Abastecimento. Produtos e Serviços. Agricultura Familiar. 2012.

Disponível em: $<$ http://www.conab.gov.br/ conteudos.php?a=1125\&t=2>. Acesso em: 15 mar. 2012 .

CREVELIN, S. A.; SCALCO, A. R. Projeto "Agricultura familiar gado de leite: melhorias ocorridas em uma propriedade familiar no município de Tupã". In: CONGRESSO DA SOBER: CONHECIMENTOS PARA A AGRICULTURA DO FUTURO. 45 Anais... Londrina, PR, 2007.

FAO - Organización de las Naciones Unidas para la Alimentación y la Agricultura. Buenas prácticas en el manejo de extensión en America Central. Roma, 2011. Disponível em: <http://www.fao.org/documents/card/es/c/04fef $\quad 85 \mathrm{~d}$-adbf-5f5cb58a-337f5bd7ce44/>. Acesso em: 21 abr. 2015.

FAO - Organização das Nações Unidas para a Alimentação e Agricultura. Representação da FAO no Brasil. O aumento populacional e os desafios da segurança alimentar. FAO debate produção e demanda mundial por alimentos no Fórum Sebrae de Conhecimento. Brasília, nov. 2012. Disponível em: <https://www.fao.org.br/apdsa.asp>. Acesso em: $1^{\circ}$ fev. 2013. 
FERRAZ JUNIOR, E. G. A importância da pesquisa e extensão nas Universidades e as implicações de tais ações para a humanidade. JURISWAY - Sistema Educacional On-Line. Sala dos Doutrinadores. Estudos \& Pesquisas, agosto/2010. Disponível em: $<$ http://www.jurisway.org.br/v2/dhall. asp?id_dh=4493>. Acesso em: 16 jun. 2014.

GUANZIROLI, C. et al. Agricultura familiar e reforma agrária no século XXI. FAO/MDA. Rio de Janeiro: Garamond, 2001.

GUILHOTO, J. J. et al. Agricultura familiar na economia: Brasil e Rio Grande do Sul. Estudos NEAD 9. Brasília, DF: MDA, 2005. 44 p. Disponível em: <http://www. nead.org.br/index.php?acao=biblioteca $>$. Acesso em: 15 jun. 2012.

GUILHOTO, J. J. et al. A importância do agronegócio familiar no Brasil. $R E R$, Rio de Janeiro, v. 44, n. 3, p. 355-382, 2006. Disponível em: $<$ http://www. scielo.br/pdf/resr/v44n3/a02v44n3.pdf >. Acesso em: 17 jun. 2011.

INCRA - Instituto de Colonização e Reforma Agrária. Portaria $n^{\circ} 52$, de 6 de novembro de 1997. Cópia do Documento. Serviço Público Federal, Dourados, MS, 2011 a.

LAMAS, F. M. et al. Diagnóstico dos assentamentos rurais de Mato Grosso do Sul. Dourados, MS: Embrapa Agropecuária Oeste. 2000. 32 p. (Embrapa Agropecuária Oeste, Documentos 18).

LAZZARETTI, M. A. Ação coletiva em assentamentos de reforma agrária: processos de organização dos trabalhadores rurais. Cascavel, PR: Edunioeste, 2003.

MACMILLAN, T.; BENTON, T. G. Engage farmers in research: A new wave of small-scale agricultural innovation will boost yields and protect the planet, contend. Nature. Coment, v. 509, maio/2014, p. 25-27. 
Disponível em: <http: //www.nature.com/news/agriculture-engagefarmers-in-research-1.15108>. Acesso em: 13 jun. 2014.

MANZANAL, M.; SCHNEIDER, S. Agricultura familiar y politicas de desarrollo rural em Argentina y Brasil (análisis comparativo, 19902010). Revista Interdisciplinaria de Estudios Agrarios. UBA: Argentina, n. $34,2011$.

PIVETTA, H. M. F. et al. Ensino, Pesquisa e Extensão Universitária: em busca de uma integração efetiva. Linhas Críticas, v. 16, n. 31, p. 377390, jul./dez. $2010 . \quad$ Disponível em: <http://educa.fcc.org.br/scielo.php?pid=S1981-043120 10000200011 \&script=sci_arttext\&tlng=pt $>$. Acesso em: 14 jun. 2014.

SANGALLI, A. R. Assentamento Lagoa Grande, em Dourados, MS: aspectos socioeconômicos, limitações e potencialidades para o seu desenvolvimento. 2013, 107 p. Dissertação (Mestrado em Agronegócios) - Universidade Federal da Grande Dourados (UFGD), Dourados, MS, 2013.

SANTOS, A. N. Assentamento rural e agricultura: acertos, impasses e perspectivas no P. A. Corona, Ponta Porã (MS). 2009, 200 p. Dissertação (Mestrado em Desenvolvimento Rural). Universidade Federal do Rio Grande do Sul (UFRGS). Porto Alegre, RS, 2009.

SANTOS, J. D. Ocupar, resistir e produzir: velhos e novos paradigmas na configuração de assentamentos rurais como alternativa de sustentabilidade. Revista Agriculturas: Experiências em Agroecologia. v. 8, n. 4. Rio de Janeiro, dez. 2011.

SILVA, J. G. da. O novo rural brasileiro. 2. ed. Campinas, SP: Unicamp IE, 2002. (Coleção Pesquisas, 1).

SILVA, R. P. Modo de produção - assentamentos rurais. Reforma Agrária em Debate:

Textos (reformaagrariaemdebate.blogspot.com/p/textos.html). Disponível em: 
$<$ http://reformaagrariaemdebate.blogspot. com.br/2011/01/ modode-producao-assentamentos-rurais.html>. Acesso em: 13 out. 2012.

SOUZA, P. M. et al. Agricultura familiar versus agricultura não-familiar: uma análise das diferenças nos financiamentos concedidos no período de 1999 a 2009. Documentos Técnico-Científicos. Revista Econômica do Nordeste-REN, Natal, RN. v. 42, n. 1, 2011.

STURZA, J. A. I.; RODRIGUES, L. S. Paisagens e recursos naturais do Cerrado: diálogos com agricultores em comunidades rurais de Rondonópolis - Mato Grosso - Brasil. Revista Brasileira de Agroecologia, v. 4, n. 2, 2009.

STURZA, J. A. I. et al. Contribuições da percepção geográfica e do serviço social para a extensão rural inovadora no assentamento rural Esperança - Rondonópolis - Mato Grosso. In: XXI Encontro Nacional de Geografia Agrária. Anais... Uberlândia: UFU, 2012.

STURZA J. A. I. Contribuição às pesquisas em extensão rural agroecológica. Revista da ANPEGE, Dourados, v. 9, n. 11, 2013.

VALADARES, A. A.; LIMA JUNIOR, A. T.; FERREIRA, B.; ALVES, F. O rural na PNAD 2008. In: CASTRO, J. A.; VAZ, F. M. (Orgs.). Situação social brasileira: monitoramento das condições de vida. Brasília: IPEA, 2011.

VILPOUX, O. F.; OLIVEIRA, M. A. C. de. Governanças na agricultura familiar: mercados, contratos, redes e cooperativismo. In: VILPOUX, O. F. (Org.). Sustentabilidade na agricultura familiar. Curitiba, PR: CRV, 2011.

Submetido em 28/09/2014

Aprovado em $07 / 12 / 2015$ 


\section{Sobre os autores}

\section{Madalena Maria Schlindwein}

Doutora em Economia Aplicada. Professora do Programa de Pós-Graduação em Agronegócios, da Faculdade de Administração, Ciências Contábeis e Economia da Universidade Federal da Grande Dourados (UFGD). Endereço: Rua Ponta Porã, 455, Apto. 204, Vila Aurora. 79823-070 - Dourados - MS - Brasil.

E-mail: madalenaschlindwein@ufgd.edu.br

\section{Adriana Rita Sangalli}

Mestre em Agronegócios. Técnica Administrativa da Universidade Estadual de Mato Grosso dos Sul (UEMS). Pesquisadora na Universidade Federal da Grande Dourados (UFGD). Endereço: Rua Barão do Rio Branco, 395, Apto. 33 - E, Jardim Tropical. 79820011 - Dourados - MS - Brasil.

E-mail: adrianars@uems.br

\section{Manfredo Rode}

Mestre em Agronegócios. Docente da Faculdade de Administração, Ciências Contábeis e Economia da Universidade Federal da Grande Dourados (UFGD). Endereço: Rua Floriano Peixoto, 888, Centro. 79824-090 - Dourados - MS - Brasil.

E-mail: manfredorode@ufgd.edu.br

\section{Vanda Maria Rubert Stefanello}

Discente do Curso de Ciências Contábeis da Faculdade de Administração, Ciências Contábeis e Economia da Universidade Federal da Grande Dourados (UFGD). Bolsista de Extensão. Endereço: Alameda Dourados, 225, Jardim Mônaco. 79826-620 - Dourados - MS - Brasil.

E-mail: vandastefa@hotmail.com. 